\title{
Spot Welding Controller
}

\author{
Aishwarya Chavan ${ }^{1}$, Shubhangi Soundalkar ${ }^{2}$, Bhagyashri Ranveer ${ }^{3}$, Ganesh L.Dake ${ }^{4}$ \\ Dept. of E\&TC, DIEMS, Aurangabad ${ }^{1,2,3}$ \\ Asst. Prof, Dept. of E\&TC, DIEMS, Aurangabad ${ }^{4}$
}

\begin{abstract}
Resistance spot welding (RSW) is a process in which contacting metal surfaces are joined by the heat obtained from resistance to electric current. Work pieces are held together under pressure exerted by electrodes. The process uses to shaped copper alloy electrodes to concentrate welding current into a small spot and to simultaneously clamp the sheets together. In industries at the working time some accidents happens due to machine dose not contains any controlling part. Also there a problem of less accuracy occurs in some of the products. That's just because of operator cannot find the instant at which electrodes capacity of welding gets over.Also problem occurs in variable distribution of water pressure, air pressure, so the requirement is we have to detect such condition \& machine should be stop. So the project contains PIC16F877 Controller which is going to control all such conditions. When the air, water pressure will vary below or above the range the buzzer will on machine power will off. At the input side maximum count of spots we can provide through functional keys.Simultaneously LCD will show the count of weld spots product. When a limit of count will exceed the machine will stop automatically. So the operator can move for maintenance. After that to start the machine there is a reset switch is designed and while working to stop machine there also one emergency switch we are going to add.
\end{abstract}

Keywords: PIC16F877 Controller; Closed loop system; System lifetime; System maintenance Algorithm.

\section{INTRODUCTION}

Resistance spot welding (RSW) is a technique generally used to bond metal shaped into sheets no thicker than $3 \mathrm{~mm}$. Unlike other welding techniques spot welding can creates precise bonds without generating excessive heating that can affect the properties of the rest of the sheets. This is achieved by delivering a large amount of energy in a short time in order to create controlled and reliable welds.

Typical spot welding machines make use of two copper alloy electrodes that are positioned over the area where the bond is to be made. The two sheets of metal that are welded are clamped by the two electrodes while a large electric current is run through them. The technique is also known as 'resistance spot welding', because the amount of heat delivered on the spot is directly related to the resistance between the electrodes, the amplitude of the current and duration of the applied electric current. The electric current required for such application is produced with the help of a step down transformer which lowers the voltage and increase the current (the voltage between two electrodes rarely exceeds 1.5 volts).

Spot welding works on the principle that of joule E= IR2 (E=energy, I=current, R=Resistance) a low volt high current is passed through work which heats the work that is clamp firmly between copper electrodes where sheets are met to each other (R) is much more than other contacts hence much heat is produced inside work $\&$ it fuses work from inside, after a predetermined time current is stopped then fused metal solidifies $\&$ a proper joint build up under pressure of electrodes, this is all about how exactly the machine is.
Spot welding machine is an open loop system. This project is going to implement proposed system that is 'Spot Welding Controller' which involves the feedback \& provides a total control to the system.

\section{RELATED WORK}

The existing spot welding machine consist the feature like current value can be set in KA \& other parameter. After the product goes to weld, on starting of welding cycle controller gets feedback on every half cycle from feedback coil connected to secondary of machine. And correction applies for the next half cycle.it tries to adjust firing angle to get correct value welding current. Whatever the current flows in one cycle gets measured \& compared with the set value. The alarm is provided as a output for to detect faulty welding. Faulty welded piece will be sort out.Using a toroidal coil, the current wave form is reconstructed from the output signal. It is then transformed into an RMS effective value. The Weld controller then compares this effective value with the set current value. The weld current is corrected with every half cycle through phase conversion and trigger pulse oscillation. The result is smooth, consistent secondary welding current delivered at the weld regardless of the line voltage fluctuations.

The three main parameters that govern spot weld quality are current, time and force. Proper control of these parameters will generate the required heat for melting the metal and development of spot weld nugget. Increase in spot weld nugget diameter has been shown to increase spot weld strength [2]. Increase in the welding current was 
found to increase the weld nugget diameter, which in turn was done in order to control the weld parameters like increases the weld strength until expulsion occurs [3]. current, force, time only. These consist, the feedback is Similarly increase in weld time also increases weld nugget provided to get the correct value welding current. The diameter and weld strength until occurrence of expulsion current is measured \& compared with the set value. [4]. Expulsion is a phenomenon that occurs when molten Current monitoring \&controlling is there \& in case of metal is expelled from the weld zone during welding; due faulty welding alarm is provided. Somewhat research is to force caused by weld nugget expansion (growth) done for the large scale spot welding machines, to improve exceeds the supplied electrode force. On the other hand, the consistency, again for the tip voltage measurement \& decrease in electrode force will increase the weld nugget dc power supply control also.

diameter and the weld strength until expulsion occurs [5].

For decades current and time have been the vital control But the requirement is, in industries at the working time parameters in the industry due to the availability of some accidents happens due to machine dose not contains electronic controllers which allow the development of any controlling part. Also there a problem of less accuracy closed loop control system. Electrode force was not a occurs in some of the products. That's just because of control parameter because of the use of the pneumatic operator cannot find the instant at which electrodes system to supply force during welding. Pneumatic system, capacity of welding is over and results in the improper being a mechanical system, does not allow the welding on work pieces or quality of weld decreases.

development of a closed loop control system; therefore force could not be monitored or controlled during spot Also problem occurs in the case of variable distribution of welding [6].

Thus from the analysis of the different research papers \& water pressure, air pressure. So the requirement is we have to detect such condition \& machine should be stop at the from the existing system we found that, this total research

\section{SYSTEM DEVELOPMENT}

\section{A. Hardware:}

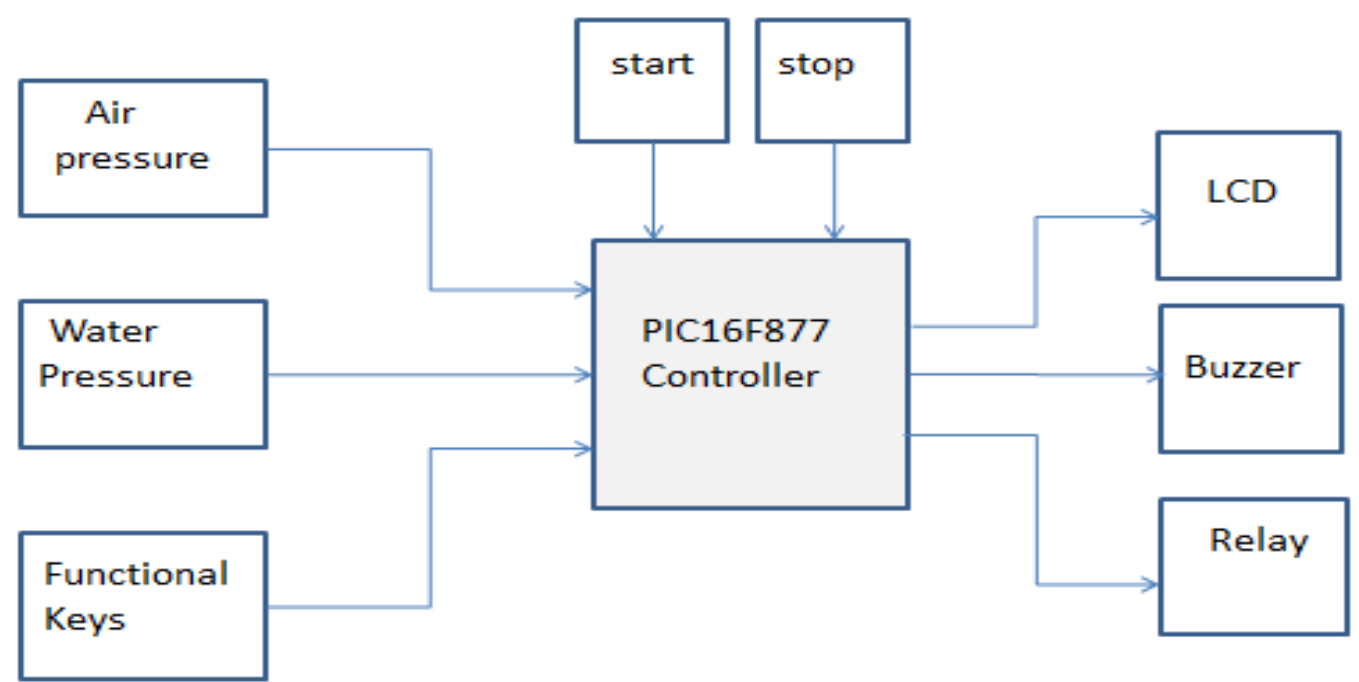

Fig.1: Block diagram of proposed system.

The proposed system is developed with the help of the buzzer will on. Again the flex sensor is used to count microcontroller PIC16. PIC controller is used to control the no. of welds.Functional keys are one of the inputs these physical parameters as well as to provide the fixed given to controller. It will provide the maximum count count of no. of welded components. This takes the Analog value to the controller initially taken from the operator. pressure inputs as well as the maximum count number of Flex sensor will provide the input to the controller when welds so to stop the machine at desired instances for paddle is pressed by operator while preparing for one further maintenance. The three inputs air, water pressure\& weld. If the maximum count is reached by the counter the functional keys are given to PIC16F877controller. controller will provide the output in the form of Whatever the air, water pressure is given to the machine buzzer/alarm, It will show the required message on LCD that the controller will monitor, will show on LCD display display, In order to change the electrode. As well as the and if pressure goes beyond or below the specified range Relay will energized and machine will stop at that instant. 


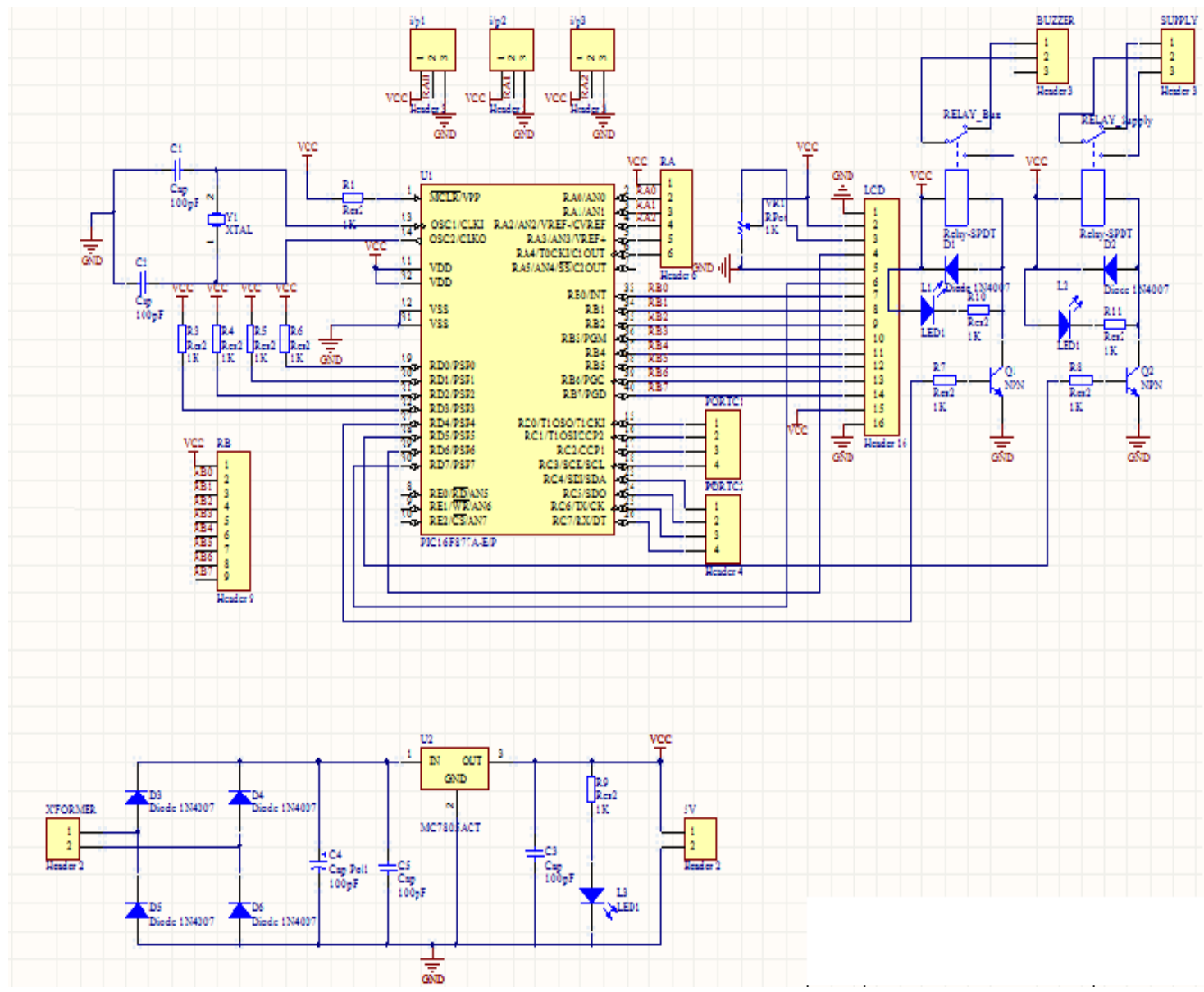

Fig.2:Circuit diagram of proposed system

B. System Flow

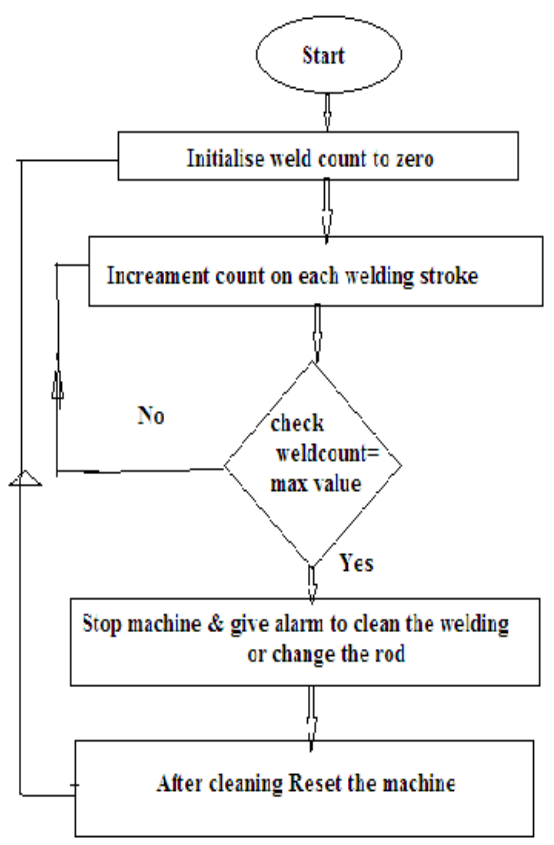

Fig.3: Pressure measurement \& control

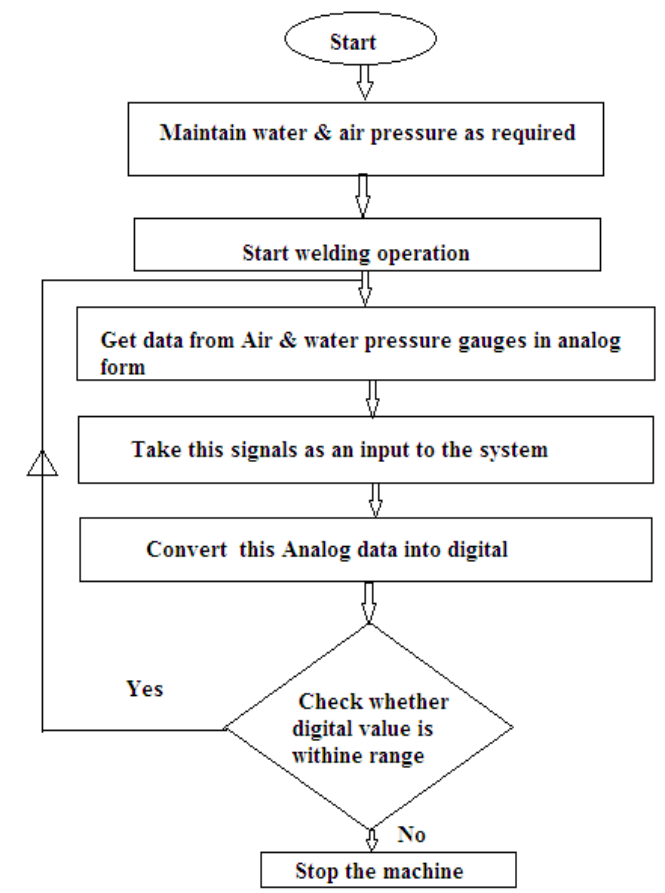

Fig.4: Counting mechanism \& control 
C. Algorithm

1. Start Machine

2. Display Welcome

Display Air, Water pressures continue.

3. Initialise counter to zero value.

4. Set up the maximum count through functional keys.

5. Check

If, $($ Count $=$ Max Count $)$

Then,

-Buzzer/Alarm ON.

\author{
-Machine Stop. \\ Else, \\ Continue counting \\ \& check \\ If $($ Pressure $=$ within a required range $)$ \\ -continue measure \& display \\ Else, \\ - Buzzer/Alarm ON. \\ -Stop machine
}

\section{SIMULATION RESULTS}

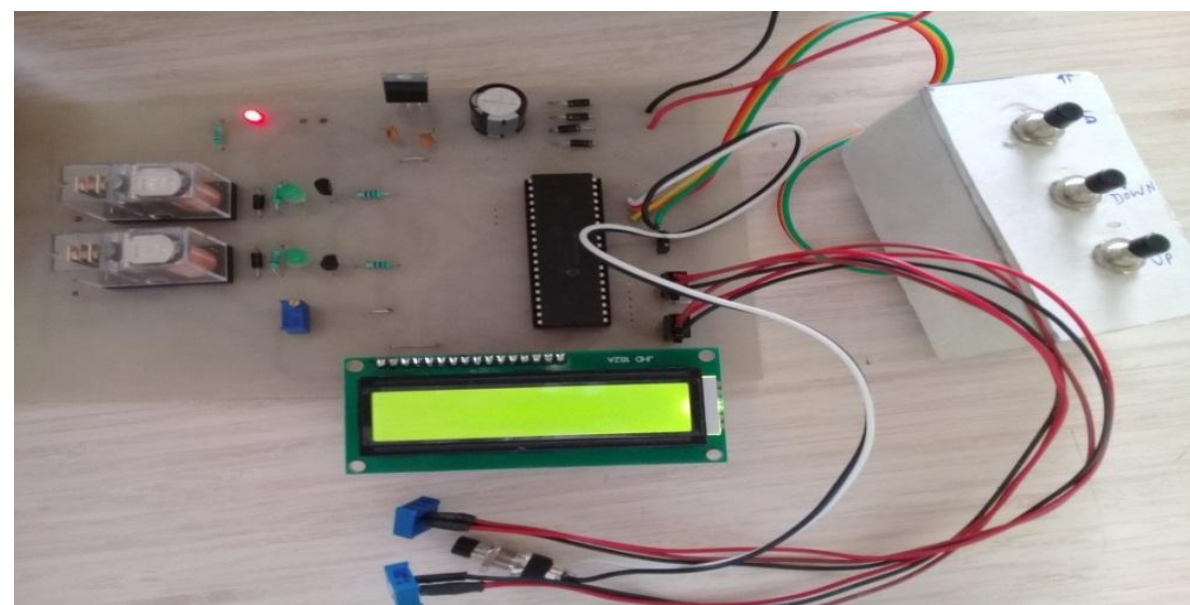

Fig.5: Designed System Configuration

After testing the algorithm and code on the designed circuitry, the following simulation results observed.

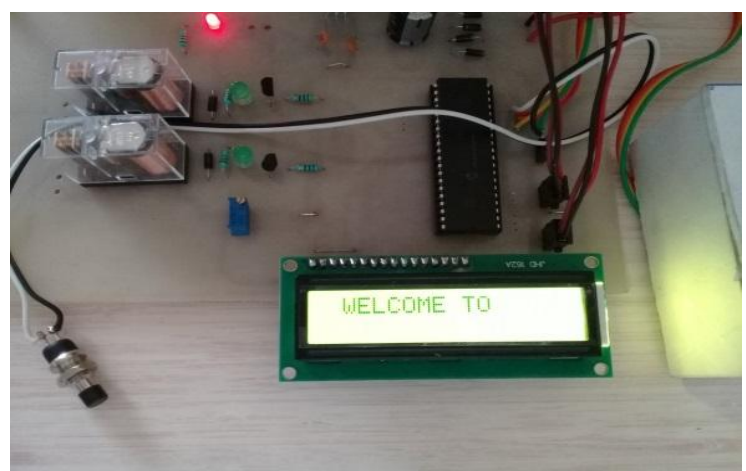

Fig.6: LCD shows message 'WELCOME TO’

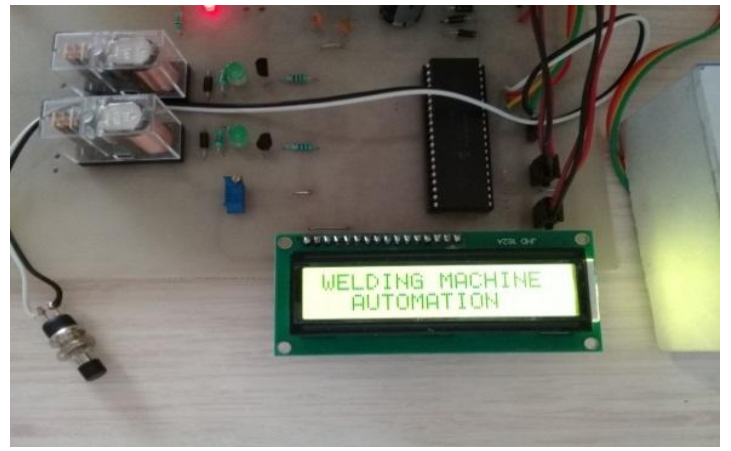

Fig.7: LCD shows 'WELDING MACHINE AUTOMATION'
Experiment 1: Air and Water pressure measurement and control

In this experiment we designed the module to test purpose. After testing we got the different readings of voltages to the different value of resistances. Similarly for the actual system design the signals from the air pressure and water pressure gauges are tapped and given to the controller, then this shows the reading of both the pressure and if it goes beyond or below the range(400 to 800PSI) it shows the message to check air/ water pressure makes the buzzer ON and system power becomes OFF.

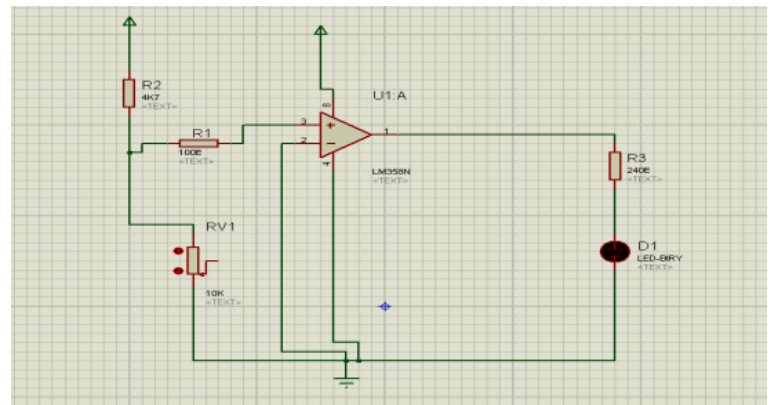

Fig.8: Module of Pressure Measurement

Figure shows the module of pressure measurement. Contains op-amp compares the incoming input with reference pressure value which is set here using resistors. And the table value shows reading of this module. 


\section{IJARCCE}

\begin{tabular}{|l|l|l|}
\hline Sr. no. & Input Resistance & $\begin{array}{l}\text { Output } \\
\text { voltage }\end{array}$ \\
\hline 1. & Minimum $(0 \mathrm{Ohms})$ & $4.34 \mathrm{~V}$ \\
\hline 2. & Maximum $(9.9 \mathrm{~K} \mathrm{Ohms})$ & $11.8 \mathrm{~V}$ \\
\hline
\end{tabular}

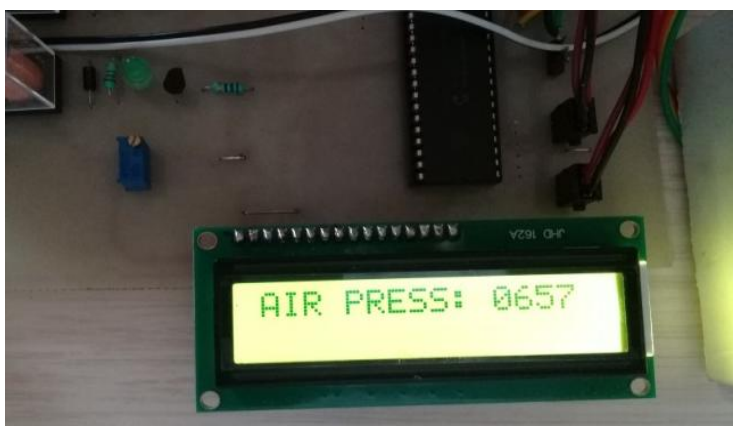

Fig.9: Displays Air Pressure reading

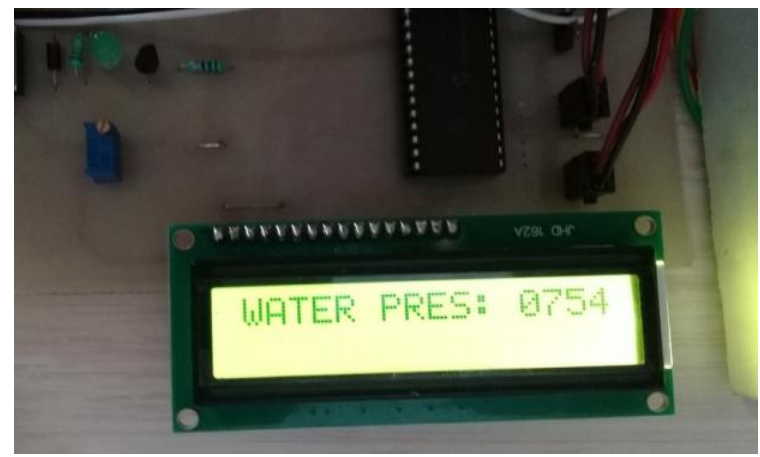

Fig.10: Displays water pressure reading

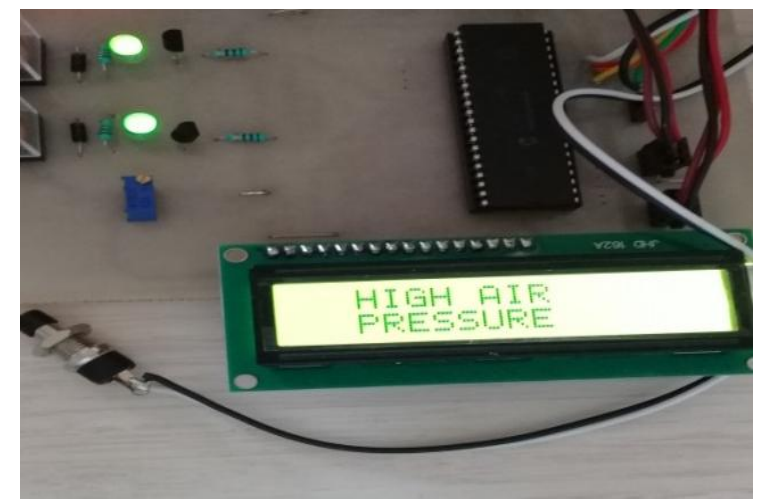

Fig.11:Displays 'HIGH AIR PRESSURE'

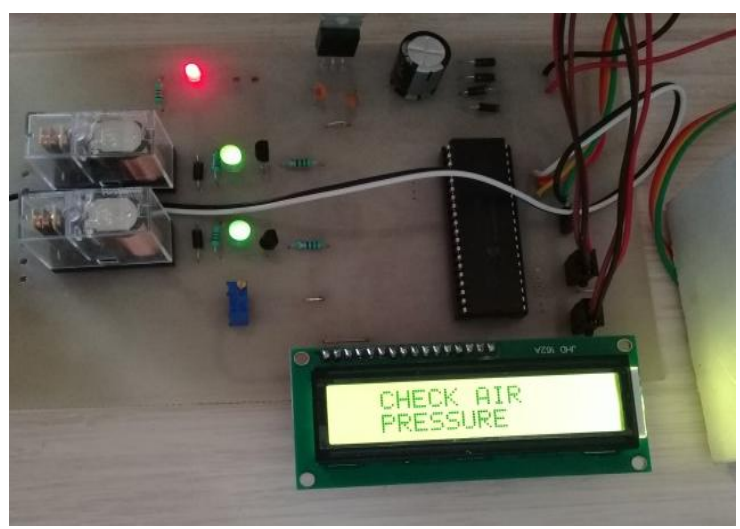

Fig.12:Displays ‘CHECK AIR PRESSURE’

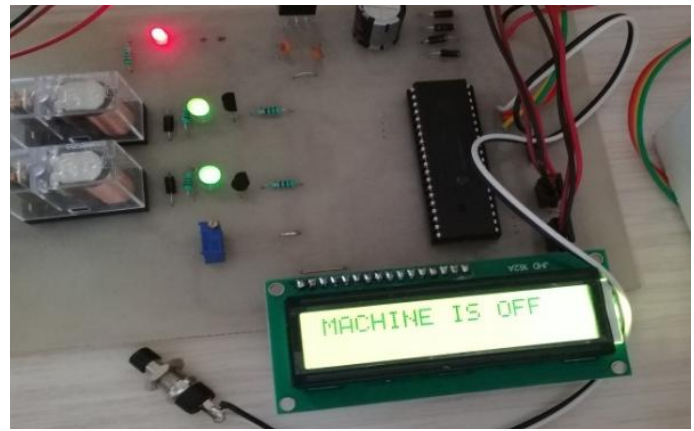

Fig.13: Displays ' MACHINE IS OFF'

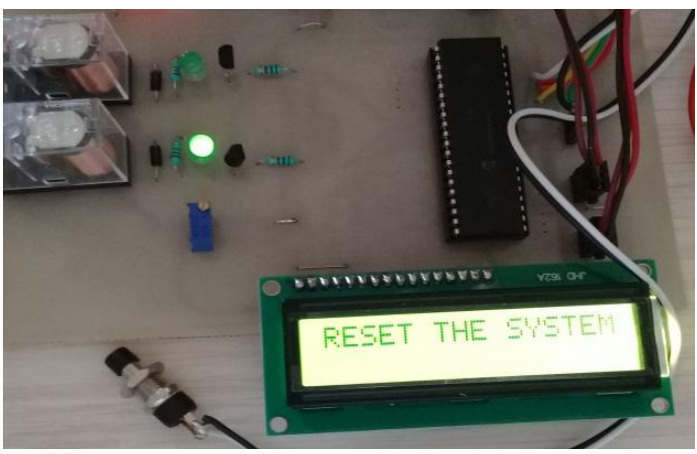

Fig.14: Displays 'RESET THE SYSTEM'

\section{Experiment 2: Spots counting and controlling}

In designed module while testing it is observed that when flex sensor senses the input at the output side the LED goes ON. This we can consider as a one count.

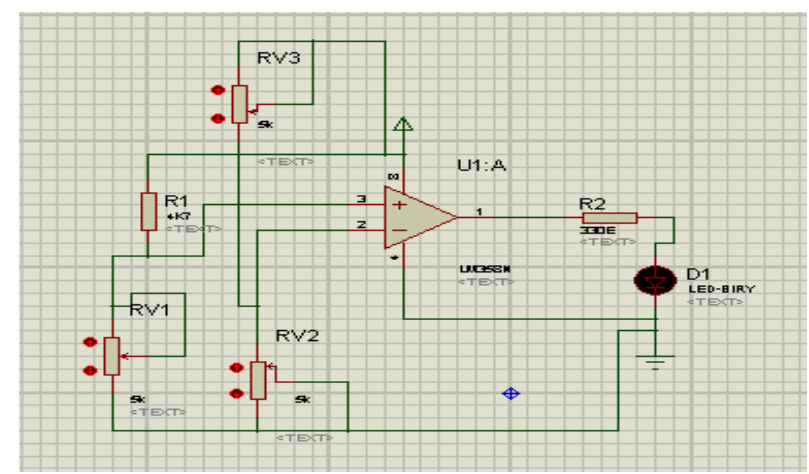

Fig.15: Module of counting mechanism.

Similarly in the actual system design, it provides the facility to set the maximum count

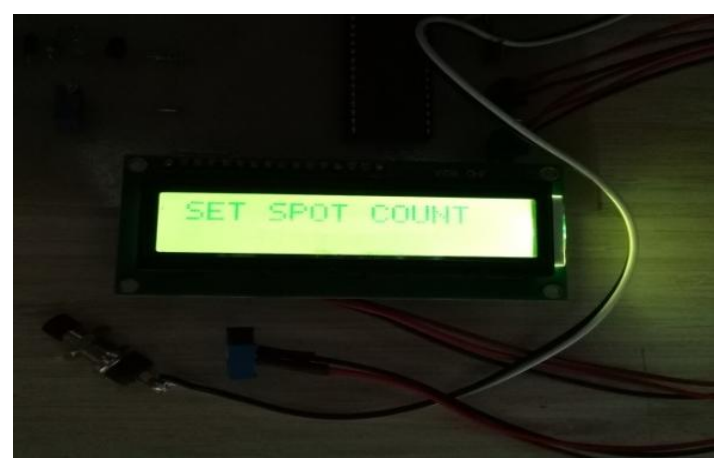

Fig.16: Displays for maximum spot count. 


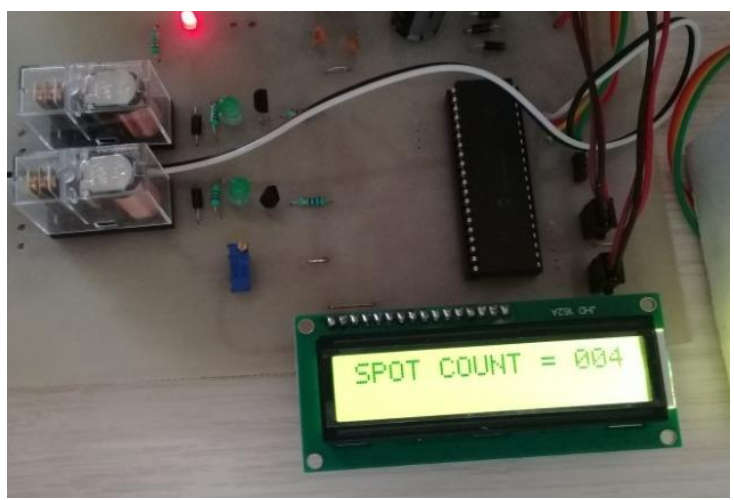

Fig.17: Displays for maximum spot count set is four.

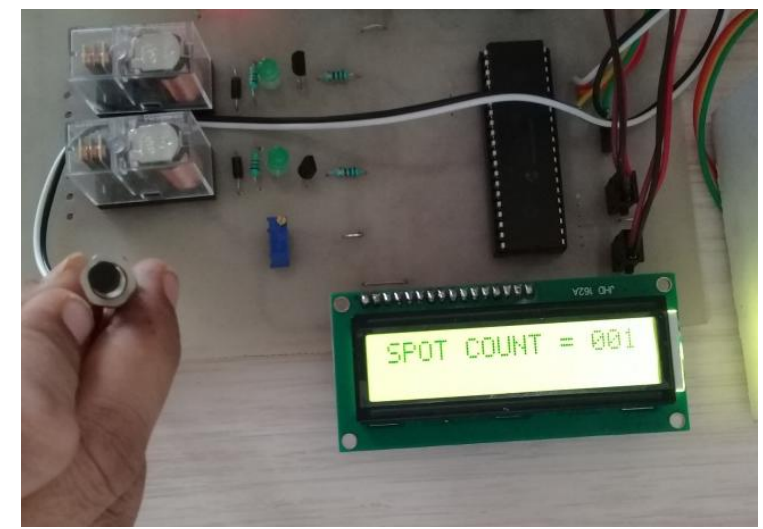

Fig.18: Displays decremented spot count to one.

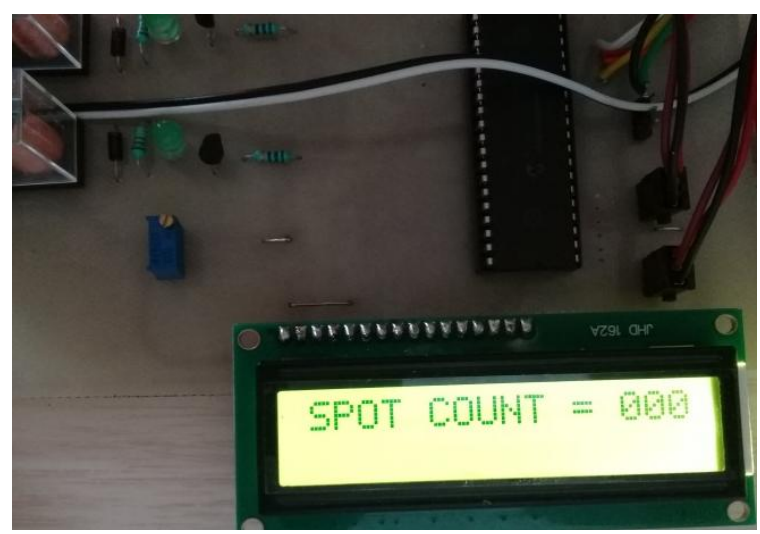

Fig.19: Displays the decremented count to zero.

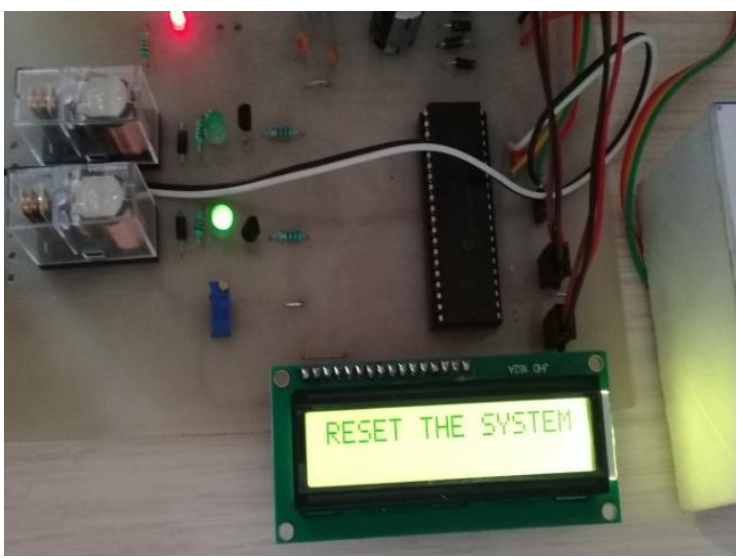

Fig.19: RESET THE SYSTEM

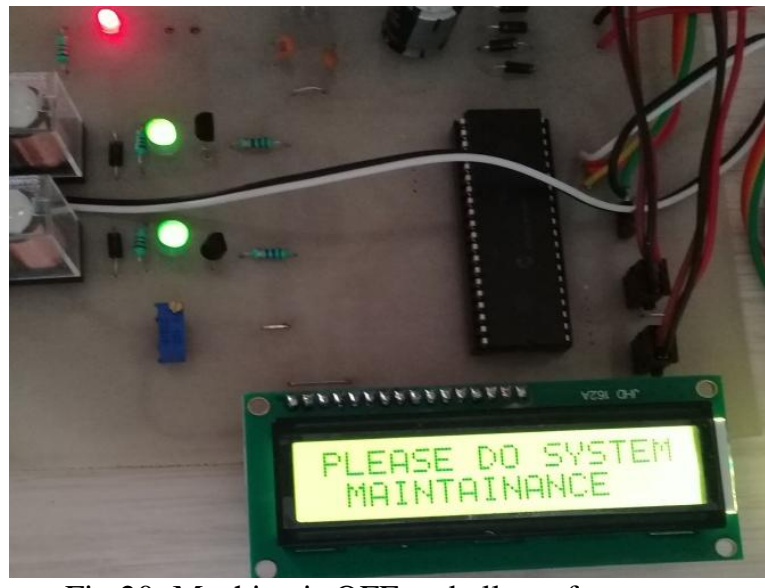

Fig.20: Machine is OFF and allows for system maintenance

This way we have tested these experiments and from this experiment it is observed that according to the designed algorithm and code system can measure the both pressure quantities and controls it. Again we can set maximum number of spots\& as it gets the input from flex sensor which is connected to paddle of machine then count decreases. then buzzer becomes $\mathrm{ON}$ and machine power becomes OFF.

\section{CONCLUSION}

The simulation results showed that the proposed algorithm performs better. The use of PIC16F877 controller provides reliability and fast response. The proposed algorithm provides the smart controlling to the entire machine and maximizes the lifetime of machine and provides safety to human operators. This provides effective control over the specified ranges of air and water pressure. This provides the facility that gives a certain time to the operator to changing and cleaning of electrode of machine after the certain fix no. of spots. According to requirement for the industrial application we have selected the required components which are being used for the system development.

\section{ACKNOWLEDGEMENT}

Completion of your project is a task which would have not accomplished without cooperation and help from our guide. At the outset, we wish to express our deep sense of gratitude to our guide, Prof. G. L. Dake for his guidance and constant encouragement, without which it would have not been possible.

We would like to thank Prof. R. M. Autee Head, Electronics \& Communication Department for his encouragement, guidance and allowing us to use the all facilities in the department. We are very much thankful to all our faculty members whose presence always inspires us to do better. At last we also thankful to our friends who have helped us in completion of the report. 


\section{REFERENCES}

[1] Control \& power supply for resistance spot welding Meranda Salem, The University of Western Ontario. Supervisor: Dr. L. J. Brown. The University of Western Ontario.

[2] Aravinthan and C. Nachimani, "Analysis of spot weld growth on mild and stainless steel”, Welding Journal, 90, 2011, pp 143-147.

[3] S.Aslanlar, A.Ogur, U.Ozsarac and E.Ilhan.E, "Effect of welding current on mechanical properties of galvanized chromided steel sheet in electrical resistance spot welding", Materials and Design, 28, 2007, pp 2-7.

[4] M.Pouranvari and S.P.H Marashi, "Factors affecting mechanical properties of resistance spot welding", Materials Science and Technology, 261, 2010, pp 1137-1144.

[5] X.Zhang, G.Chen, Y.Zhang and X.Lai, "Improvement of resistance spot weldability for dual-phase (DP600) steel using servo gun", Journal of Materials Processing Technology, 2009, pp 2671-2675.

[6] Effect of Force Control During Spot Welding on Weld Properties. School of Engineering, KDU University College ,Department of Mechanical, Materials and Manufacturing Engineering, University of Nottingham Malaysia Campus, JalanBroga, Semenyih, 43500 Selangor, MALAYSIA. 